\title{
Energetic triazolo-triazolo-furazano-pyrazines: A promising fused tetracycle building block with diversified functionalities and properties
}

\author{
Anjali Maan ${ }^{1}$, Ramling Mathpati ${ }^{1}$, and Vikas Ghule ${ }^{1}$ \\ ${ }^{1}$ National Institute of Technology Kurukshetra
}

April 28, 2020

\begin{abstract}
In this study, high energy materials (HEMs) derived from 1,2,4-triazolo[3,4-d]-1,2,4-triazolo[3,4-f]furazano[3,4-b]pyrazine (TTFP) substituted with $-\mathrm{NH} 2,-\mathrm{NHNO} 2,-\mathrm{ONO} 2,-\mathrm{NO} 2$, and - N3 explosophoric groups were designed and computationally characterized. It is found that the TTFP is an effective molecular backbone for improving the energy content and energetic performance of the designed compounds. The effect of various explosophoric groups on energy content, density, detonation performance, and sensitivity was investigated. The energetic evaluation indicated that TTFP derivatives having $-\mathrm{NHNO} 2,-\mathrm{ONO} 2$, and $-\mathrm{NO} 2$, groups demonstrate good detonation performances and exceed the performance of TNT and RDX. Considering the energetic properties, the TTFP backbone can be regarded as an energy-rich unit, which can be substituted with suitable explosophoric groups for constructing HEMs.
\end{abstract}

\section{Introduction}

The high energy materials (HEMs) composed of nitrogen-rich heterocycles are being investigated intensively as they are proven contributing to explosive and propellant performance due to high density and energy content. ${ }^{[1-6]}$ The construction of energy-rich molecular framework with multiple carbon-nitrogen and nitrogen-nitrogen bonds and availability of position for the functional group attachment represents the forefront of research in explosive chemistry. The fusion of heterocyclic rings to form a fused ring skeleton has become one of the most useful and popular aspects to improve density and heat of formation. ${ }^{[7]}$ There are many experimental results for explosives and propellants containing fused rings demonstrated the promising and fascinating energetic properties with sufficient stability and insensitivity to mechanical stimuli. The differences in physicochemical properties of individual heterocyclic and carbocyclic rings would overcome in the fused backbone and will help to achieve better energetic performance and stability (see Fig. 1).

Growing demand for energetic materials in diverse civil, defense, and space applications has increased the need to synthesize them. In this context, the cost and hazardous nature associated with energetic materials force the use of computational approaches to screen the potential molecules before synthesis. ${ }^{[8-10]}$ Given this background, we have inserted $-\mathrm{NH}_{2},-\mathrm{NHNO}_{2},-\mathrm{ONO}_{2},-\mathrm{NO}_{2}$, and $-\mathrm{N}_{3}$ explosophoric groups in 1,2,4triazolo[3,4-d]-1,2,4-triazolo[3,4-f] furazano[3,4-b]pyrazine (TTFP) backbone (see Fig. 2). These functional groups are proven to alter the explosive performance and hence introduced in the TTFP framework for a comprehensive understanding of the structure-property relationship. The TTFP structure (molecular formula) is tetracycle consists of four fused rings including pyrazine, furazan, and two triazole rings. In the literature, the synthesis of TTFP has been reported, ${ }^{[11-14]}$ however, the design of new HEMs with TTFP backbone composed of different explosophoric groups is not known. Our objective in this paper is to address the importance of TTFP fused backbone in designing the energetic molecules and also look at the relative role of $-\mathrm{NH}_{2},-\mathrm{NHNO}_{2},-\mathrm{ONO}_{2},-\mathrm{NO}_{2}$, and $-\mathrm{N}_{3}$ groups in determining the energetic properties. 


\section{Results and discussion}

DFT calculations were carried out with the Gaussian 09 program $^{[15]}$ using widely used combination of Becke's three-parameter hybrid functional (B3) with Perdew and Wang's (PW91) non-local correlation and basis set $6-31 \mathrm{G}(\mathrm{d}, \mathrm{p}) .{ }^{[16-18]}$ All optimized structures were verified to be local minima and without imaginary frequencies. Multiwfn program ${ }^{[19]}$ was used to obtain molecular surface properties. The energetic properties of TTFP derivatives were calculated using trustworthy and established theoretical methods that are identical to previous studies ${ }^{[20-22]}$ and presented in the Supporting Information.

\subsection{Heat of formation (HOF)}

HOF is one of the crucial parameters for HEMs that is straightforwardly linked to a total $\mathrm{C}-\mathrm{N}$ and $\mathrm{N}-\mathrm{N}$ bonds and functional groups existing in the molecular framework. The higher is the HOF of HEMs, the more is the exothermic combustion, which results in the quick expansion of detonation products and rising the temperature of the combustion chamber. In recent times, high-nitrogen heterocycles and fused-heterocycles have drawn more attention in the explosive chemistry due to their exclusive energy content and dense nature. ${ }^{[23-26]}$ For TTFP, the experimental HOF is not available and hence isodesmic reaction approach was

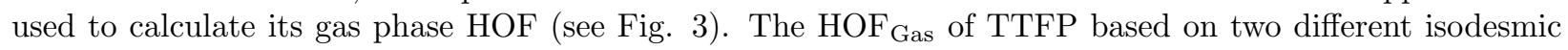
reactions were calculated to be 811.2 (see Fig. 3a) and 818.8 (see Fig. 3b) kJ/mol and shows good agreement. Table 2 summarizes the calculated HOFs for TTFP derivatives. It can be noted that all compounds display positive HOFs, with F3 (azide) ensuring the highest value of $1311.6 \mathrm{~kJ} / \mathrm{mol}$, resultantly almost double than that of F1 (TTFP). The HOF of F3 is higher in the series arising from the significant energy contribution of $-\mathrm{N}_{3}$ group. The replacement of $-\mathrm{H}$ in $\mathrm{F} 1$ with $-\mathrm{NHNO}_{2}(\mathrm{~F} 4)$ and $-\mathrm{NO}_{2}$ (F6) increases the $\mathrm{HOF}_{\text {Solid }}$ by 72 and $65 \mathrm{~kJ} / \mathrm{mol}$, respectively. The introduction of $-\mathrm{NH}_{2}$ (F2) and $-\mathrm{ONO}_{2}$ (F5) groups decreases the HOF of $\mathrm{F} 1$ by 84 and $119 \mathrm{~kJ} / \mathrm{mol}$, respectively, reveals their negative impact on $\mathrm{HOF}$ values. The effect of functional groups on the energy content is observed in the following order: $-\mathrm{N}_{3}>-\mathrm{NHNO}_{2}>-\mathrm{NO}_{2}>-\mathrm{H}>$ $-\mathrm{NH}_{2}>-\mathrm{ONO}_{2}$. The $\mathrm{HOF}_{\text {Solid }}$ for all designed compounds (F1-F6) are much greater than the TNT (-67.0 $\mathrm{kJ} / \mathrm{mol})$, RDX $(63 \mathrm{~kJ} / \mathrm{mol})$, and HMX $(76 \mathrm{~kJ} / \mathrm{mol}) \cdot{ }^{[27]}$ It is logical to envisage the importance of fused TTFP framework in significantly enhancing net input of energy of the designed compounds and reflecting greater energy content.

\subsection{Oxygen balance and density}

Oxygen balance (OB) specifies oxygen insufficiency or surplus in HEMs needed to transform all hydrogens into $\mathrm{H}_{2} \mathrm{O}$ and carbons into $\mathrm{CO}_{2}$. Compound $\mathrm{F} 5$ display $\mathrm{OB}$ value $-24.7 \%$ owing to $-\mathrm{ONO}_{2}$ groups in the structure, where other compounds have lower values ranging from $-38.4 \%$ (F6) to $-95.0 \%$ (F1). Incorporation of $-\mathrm{NHNO}_{2},-\mathrm{ONO}_{2}$ and $-\mathrm{NO}_{2}$ groups acts as reservoir of oxygen in TTFP derivatives and improves the $\mathrm{OB}$ of the corresponding compounds and may ultimately result in greater exothermicity during combustion and detonation. It has been established that increasing nitrogen content in the molecular framework leads to both improved HOFs and a greater crystal density. The replacement of more $\mathrm{CH}$ units in the ring with nitrogen atom reduces the molecular volume and enhances the mass. By the same reasoning, the fusion of heterocyclic rings should also increase density over its carbocyclic analogs and expected to have greater net density. Densities of TTFP derivatives determined using Politzer approach ${ }^{[28]}$ found between 1.84 to $1.92 \mathrm{~g} / \mathrm{cm}^{3}$. All the TTFP derivatives show better densities relative to TNT $\left(1.65 \mathrm{~g} / \mathrm{cm}^{3}\right)$ and RDX $(1.82$ $\left.\mathrm{g} / \mathrm{cm}^{3}\right)$. Among them, F2, F4, and F6 have the highest density of $1.92 \mathrm{~g} / \mathrm{cm}^{3}$, which is superior to HMX $\left(1.90 \mathrm{~g} / \mathrm{cm}^{3}\right) .{ }^{[27]}$ Overall, $-\mathrm{NH}_{2},-\mathrm{NHNO}_{2}$ and $-\mathrm{NO}_{2}$ groups play a key role in enhancing the densities of corresponding compounds.

\subsection{Performance characteristics}

The detonation velocity $(D)$ and pressure $(P)$ are common measures of explosive performance and estimated by employing the Kamlet-Jacobs equations. ${ }^{[29]}$ For better understanding and evaluation, performance parameters of TTFP derivatives are compared with TNT and RDX. Detonation velocities ranged over 7.00 to $8.36 \mathrm{~km} / \mathrm{s}$, while detonation pressures lie between 22.01 and $32.22 \mathrm{GPa}$. Compared with TNT and RDX, TTFP derivatives are dominant to TNT $(D=6.94 \mathrm{~km} / \mathrm{s}, P=22.0 \mathrm{GPa})$ while slightly inferior with respect to 
RDX ( $D=8.60 \mathrm{~km} / \mathrm{s}, P=33.9 \mathrm{GPa}$ ). Among them, by means of better OB, high density and positive high HOF, F4-F6 exhibits higher detonation performances (D[?]8.3 km/s, P[?]32 GPa). The oxygen-free compounds (F1-F3) result in lower detonation properties but greater than those of TNT. The explosive power index (PI) of HEMs depend on the energy liberated and the volume of gases produced during detonation. The estimated PI values for TTFP derivatives lie between 78-131\% (see Table 2). The Kistiakowsky-Wilson rules ${ }^{[30]}$ were used to assume the decomposition reactions and summarized in Table S4. Compounds F4-F6 shows better PI values than TNT (116\%) due to their higher OB and HOF values.

The strength and ballistic performance of HEMs also presented using Gurney velocity $(\sqrt{2 E})$. The $\sqrt{2 E}$ values are predicted using Kamlet-Finger formula ${ }^{[31]}$ and Hardesty and Kennedy approach ${ }^{[32]}$ based on total gas-phase decomposition products per gram of molecule, their formula weight, the heat of detonation and density (see Table 2). The $\sqrt{2 E}$ values of TTFP derivatives ranged from 2.31 to $2.75 \mathrm{~km} / \mathrm{s}$ (compared with TNT $2.37 \mathrm{~km} / \mathrm{s}$ and RDX $2.83 \mathrm{~km} / \mathrm{s}$ ). It is observed that $-\mathrm{NHNO}_{2},-\mathrm{ONO}_{2}$, and $-\mathrm{NO}_{2}$ groups are fruitful for improving the $\sqrt{2 E}$ values due to their oxygen-donor nature during the combustion process. The relationship between molecular structure-performance properties is more clearly reproduced in Fig. 4 . The detonation properties ( $D$ and $P$ ), power index and Gurney velocity values strongly support the claim that introducing more nitramine, nitrate-ester, and nitro substituents are favorable for HEMs.

\subsection{Sensitivity evaluation}

The prediction of sensitivity is challenging task as it depends on the physical state of explosives (particle sizes, shapes, purity, hardness of crystals, surface roughness, lattice defects) and accidental initiation can take place with impact, friction, shock, heat, electric discharge, etc. Most of the reported sensitivity correlations are computationally based and symptomatic provide insight into factors governing sensitivity. ${ }^{[33-35]}$ According to Politzer et a ${ }^{[36,37]}$ suggestion, crystal lattice free space $([?] \mathrm{V})$ and heat of detonation $(\mathrm{Q})$ are employed to correlate with the sensitivity of designed TTFP derivatives (see Table 3). [?]V is calculated as the difference between $V_{\text {eff }}$ and $V_{\text {int }}$, which are the volumes of isolated molecules enclosed by 0.001 and 0.003 au contours, respectively. In general, the higher value of [?]V value suggests a general tendency for greater sensitivity. The calculated $\Delta \mathrm{V}$ values range from 31 to $77 \AA^{3}$. According to their $\Delta \mathrm{V}$ values, F3-F6 compounds are sensitive than RDX $\left(46 \AA^{3}\right)$ and TNT $\left(58 \AA^{3}\right)$. Among the TTFP derivatives, T5 has the highest $\Delta V$ value $\left(77 \AA^{3}\right)$ and expected to be the most sensitive. The F3-F6 compounds are more sensitive due to the presence of explosophoric $-\mathrm{N}_{3},-\mathrm{NHNO}_{2},-\mathrm{ONO}_{2}$, and $-\mathrm{NO}_{2}$ groups and destabilizing the corresponding molecules due to $\mathrm{N}-\mathrm{NO}_{2}, \mathrm{O}-\mathrm{NO}_{2}$, and $\mathrm{C}-\mathrm{NO}_{2}$ trigger linkages.

Politzer et al. ${ }^{[37]}$ proposed that higher Q values are adverse from the perspective of the sensitivity of HEMs. The availability of oxygen in the molecule (better oxygen balance) produces more $\mathrm{CO}_{2}$ and $\mathrm{H}_{2} \mathrm{O}$ in the detonation process and result in higher $\mathrm{Q}$ values. The calculated $\mathrm{Q}$ values for TTFP derivatives range from 911-1431 cal/g (RDX $1500 \mathrm{cal} / \mathrm{g})$. The $-\mathrm{NHNO}_{2}$ (F4), $-\mathrm{ONO}_{2}$ (F5), and $-\mathrm{NO}_{2}$ (F6) groups responsible for better $\mathrm{OB}$ and higher $\mathrm{Q}$ values in resultant compounds, cause of higher sensitivity. The absence of oxygen in F1-F3 compounds release $\mathrm{C}(\mathrm{s}), \mathrm{H}_{2}(\mathrm{~g})$, and $\mathrm{N}_{2}(\mathrm{~g})$ as decomposition products and result in lower value of Q. Inspecting the [?]V and Q values, one could infer that the stability decreases in the order of F5 > F6 [?] $\mathrm{F} 4>\mathrm{F} 3>\mathrm{F} 1>\mathrm{F} 2$.

\section{Conclusions}

DFT calculations were executed to calculate the energetic properties of designed TTFP derivatives. The fusion of triazole and furazan rings in the TTFP backbone results in highly endothermic HOFs. It was observed that these derivatives are reasonable materials with HOFs $>563 \mathrm{~kJ} / \mathrm{mol}$, densities $>1.84 \mathrm{~g} / \mathrm{cm}^{3}$, detonation velocities $>7.00 \mathrm{~km} / \mathrm{s}$, and pressures $>22.01 \mathrm{GPa}$, which exceed to that of TNT. In line with the calculated energetic properties and sensitivity data, attachment of $-\mathrm{NHNO}_{2},-\mathrm{ONO}_{2}$, and $-\mathrm{NO}_{2}$ groups add better performance, $-\mathrm{NH}_{2}$ group enhance insensitivity and $-\mathrm{N}_{3}$ group favorable for energy content. Taking into account the manifold requirements of performance and safety towards external stimuli for HEMs, the TTFP fused backbone is more suitable due to its organic CHNO ingredient and energy-content.

\section{Supporting Information}


Computational details, selective structural parameters, and parameters related to the calculation of energetic properties of TTFP derivatives are given in the Supporting Information.

\section{Author Information}

Corresponding author: E-mail: gvd@nitkkr.ac.in (Vikas D. Ghule)

\section{Acknowledgments}

Anjali thank UGC-CSIR, Ministry of Human Resource Development, Government of India for Junior Research Fellowship. RSM thank Armament Research Board, Defence R\&D Organization, DRDO for research fellowship (No. ARMREB/CDSW/2019/211).

\section{Conflict of Interest}

The authors declare no conflict of interest.

\section{References}

1. D. E. Chavez, M. A. Hiskey, R. D. Gilardi, Org. Lett.2004, 6 , 2889.

2. R. P. Singh, R. D. Verma, D. T. Meshri, J. M. Shreeve, Angew. Chem. Int. Ed. $2006,45,3584$.

3. R. W. Millar, J. Hamid, R. Endsor, P. F. Swinton, J. Cooper,Propellants, Explos. Pyrotech. 2008 , 33,66 .

4. N. Fischer, D. Izsak, T. M. Klapotke, S. Rappengluck, J. Stierstorfer, Chem. Eur. J. 2012 , 18 , 4051.

5. Q. Zhang, C. He, P. Yin, J. M. Shreeve, Chem. Asian J.2014, 9 , 212.

6. P. Yin, Q. Zhang, J. M. Shreeve, Acc. Chem. Res. $2016,49,4$.

7. H. Gao, Q. Zhang, J. M. Shreeve, J. Mater. Chem. A2020 , 8, 4193.

8. W. Zheng, N. B. Wong, W. Wang, G. Zhou, A. Tian, J. Phys. Chem. A 2004, $108,97$.

9. X. Zhang, W. Zhu, T. Wei, C. Zhang, H. Xiao, J. Phys. Chem. C2010, $114,13142$.

10. P. Politzer, P. Lane, J. S. Murray, Cent. Eur. J. Energ. Mater.2013 , 10 , 305.

11. G. K. Khisamutdinov, V. L. Korolev, T. N. Parkhomenko, V. M. Sharonova, E. S. Artem'eva, I. Sh. Abdrakhmanov, S. P. Smirnov, B. I. Ugrak, Russ. Chem. Bull. 1993, 42 , 1700.

12. A. B. Sheremetev, I. L. Yudin, Russ. Chem. Rev. 2003 ,72, 87.

13. A. B. Sheremetev, V. L. Korolev, A. A. Potemkin, N. S. Aleksandrova, N. V. Palysaeva, T. H. Hoang, V. P. Sinditskii, K. Yu. Suponitsky,Asian J. Org. Chem. 2016 , 5, 1388.

14. D. B. Lempert, A. B. Sheremetev, Russ. Chem. Bull.2018, 67, 2065.

15. M. J. Frisch, G. W. Trucks, H. B. Schlegel, G. E. Scuseria, M. A. Robb, J. R. Cheeseman, G. Scalmani, V. Barone, G. A. Petersson, H. Nakatsuji, X. Li, M. Caricato, A. Marenich, J. Bloino, B. G. Janesko, R. Gomperts, B. Mennucci, H. P. Hratchian, J. V. Ortiz, A. F. Izmaylov, J. L. Sonnenberg, D. WilliamsYoung, F. Ding, F. Lipparini, F. Egidi, J. Goings, B. Peng, A. Petrone, T. Henderson, D. Ranasinghe, V. G. Zakrzewski, J. Gao, N. Rega, G. Zheng, W. Liang, M. Hada, M. Ehara, K. Toyota, R. Fukuda, J. Hasegawa, M. Ishida, T. Nakajima, Y. Honda, O. Kitao, H. Nakai, T. Vreven, K. Throssell, J. A. Montgomery Jr, J. E. Peralta, F. Ogliaro, M. Bearpark, J. J. Heyd, E. Brothers, K. N. Kudin, V. N. Staroverov, T. Keith, R. Kobayashi, J. Normand, K. Raghavachari, A. Rendell, J. C. Burant, S. S. Iyengar, J. Tomasi, M. Cossi, J. M. Millam, M. Klene, C. Adamo, R. Cammi, J. W. Ochterski, R. L. Martin, K. Morokuma, O. Farkas, J. B. Foresman, D. J. Fox, Gaussian 09 , Revision E.01, Gaussian, Inc., Wallingford, CT,2013 .

16. A. D. Becke, J. Chem. Phys. 1993, $98,1372$.

17. J. P. Perdew, Y. Wang, Phys. Rev. 1992, 45, 13244.

18. M. J. Frich, J. A. Pople, R. Krishnam, J. S. Binkley, J. Chem. Phys. 1984, 80 , 3265.

19. T. Lu, F. Chen, J. Comput. Chem. 2012, 33 , 580.

20. V. D. Ghule, J. Phys. Chem. A 2012 , 116, 9391.

21. V. D. Ghule, Mol. Phys. 2013 , 111, 95.

22. A. Nirwan, A. Devi, V. D. Ghule, J. Mol. Model. 2019 ,25, 315. 
23. R. D. Chapman, W. S. Wilson, J. W. Fronabarger, L. H. Merwin, G. S. Ostrom, Thermochimica Acta 2002, 384, 229 .

24. Y. Huang, Y. Zhang, J. M. Shreeve, Chem. Eur. J. 2011 ,17, 1538.

25. Q. Wu, W. Zhu, H. Xiao, Struct. Chem. 2013, 24, 1725.

26. S. Li, Y. Wang, C. Qi, X. Zhao, J. Zhang, S. Zhang, S. Pang,Angew. Chem. Int. Ed. 2013, 52, 14031.

27. D. M. Badgujar, M. B. Talawar, S. N. Asthana, P. P. Mahulikar,J. Hazard. Mater. 2008 , 151 , 289.

28. P. Politzer, J. Martinez, J. S. Murray, M. C. Concha, A. Toro-Labbe,Mol. Phys. 2009 , 107 , 2095.

29. M. J. Kamlet, S. J. Jacobs, J. Chem. Phys. $1968,48,23$.

30. J. Akhavan, The Chemistry of Explosives, Second ed., RSC Paperbacks, 2004.

31. M. J. Kamlet, M. Finger, Combust. Flame, 1979 ,34, 213.

32. D. R. Hardesty, J. E. Kennedy, Combust. Flame 1977 ,28 , 45.

33. P. Politzer, J. S. Murray, Detonation performance and sensitivity: a quest for balance. In: Advances in quantum chemistry, Elsevier, 2014, $69,1$.

34. Z. X. Chen, H. M. Xiao, Propellants, Explos. Pyrotech. 2014,39 , 487.

35. S. Zeman, M. Jungova, Propellants, Explos. Pyrotech. 2016, 41, 426.

36. P. Politzer, J. S. Murray, J. Mol. Model. 2014,20 , 2223.

37. P. Politzer, J. S. Murray, J. Mol. Model. 2015 ,21, 262.

\section{List of Tables}

Table 1 . Calculated energy content data and related parameters for TTFP derivatives.

\begin{tabular}{lllllll}
\hline Compd. & $\mathbf{E}_{\mathbf{0}}(\mathbf{a u})$ & $\mathbf{Z P E}(\mathbf{a u})$ & $\mathbf{H}_{\mathbf{T}}(\mathbf{a u})$ & $\begin{array}{l}\mathbf{H O F}_{\text {Gas }} \\
(\mathbf{k J} / \mathbf{m o l})\end{array}$ & $\begin{array}{l}\mathbf{H O F}_{\text {Sub }} \\
(\mathbf{k J} / \mathbf{m o l})\end{array}$ & $\begin{array}{l}\mathbf{H O F}_{\text {Solid }} \\
(\mathbf{k J} / \mathbf{m o l})\end{array}$ \\
\hline F1 & -742.527644 & 0.1039 & 0.0100 & 811.2 & 129.0 & 682.2 \\
F2 & -853.187166 & 0.1374 & 0.0132 & 758.4 & 160.4 & 598.0 \\
F3 & -1069.559126 & 0.1103 & 0.0155 & 1484.8 & 173.2 & 1311.6 \\
F4 & -1261.951087 & 0.1432 & 0.0170 & 934.7 & 180.6 & 754.1 \\
F5 & -1301.637672 & 0.1152 & 0.0179 & 708.7 & 145.1 & 563.6 \\
F6 & -1151.306522 & 0.1081 & 0.0154 & 889.9 & 142.9 & 747.0 \\
\hline
\end{tabular}

$\mathrm{E}_{0}$ : Total energy; ZPE: Zero point energy; $\mathrm{H}_{\mathrm{T}}$ : Thermal correction; $\mathrm{HOF}_{\mathrm{Gas}}$ and $\mathrm{HOF}_{\text {Solid }}$ : Heat of formation in the gas and solid phase, respectively; $\mathrm{HOF}_{\mathrm{Sub}}$ : Heat of sublimation.

Table 2 . Calculated performance parameters for TTFP derivatives.

\begin{tabular}{lllllllll}
\hline Compd. & NC (\%) & OB $(\%)$ & Density $\left(\mathrm{g} / \mathbf{c m}^{\mathbf{3}}\right)$ & $D(\mathrm{~km} / \mathrm{s})$ & $P(\mathbf{G P a})$ & PI $(\%)$ & $\sqrt{\mathbf{2 E}}(\mathrm{km} / \mathbf{s})$ & $\sqrt{\mathbf{2 E}}(\mathrm{km} / \mathrm{s})$ \\
\hline & & & & & & & K-F method & H-K metho \\
F1 & 55.4 & -95.1 & 1.84 & 7.00 & 22.01 & 94 & 2.31 & 2.40 \\
F2 & 60.3 & -89.7 & 1.92 & 7.17 & 23.65 & 78 & 2.34 & 2.42 \\
F3 & 69.0 & -62.0 & 1.85 & 7.75 & 27.05 & 117 & 2.56 & 2.59 \\
F4 & 52.2 & -39.8 & 1.92 & 8.36 & 32.22 & 115 & 2.73 & 2.73 \\
F5 & 43.2 & -24.7 & 1.86 & 8.34 & 31.46 & 131 & 2.75 & 2.74 \\
F6 & 47.9 & -38.4 & 1.92 & 8.34 & 32.05 & 126 & 2.72 & 2.72 \\
\hline
\end{tabular}

NC: Nitrogen content; OB: Oxygen balance; D: Detonation velocity; P: Detonation pressure; PI: Power index; $\sqrt{2 E}$ : Gurney velocity.

Table 3. Calculated effective $\left(\mathrm{V}_{\text {eff }}\right)$ and intrinsic $\left(\mathrm{V}_{\text {int }}\right)$ molecular volume, crystal lattice free space $(\Delta \mathrm{V})$, 
and heat of detonation $(Q)$ of the TTFP derivatives.

\begin{tabular}{lllll}
\hline Compd. & $\mathbf{V}_{\text {eff }}\left(\AA^{\mathbf{3}}\right)$ & $\mathbf{V}_{\text {int }}\left(\AA^{\mathbf{3}}\right)$ & $\boldsymbol{\Delta}^{\boldsymbol{*}}\left(\AA^{\mathbf{3}}\right)$ & $Q(\mathbf{c a l} / \mathbf{g})$ \\
\hline F1 & 182.0 & 145.8 & 36.2 & 1093.3 \\
F2 & 200.9 & 170.2 & 30.7 & 911.7 \\
F3 & 255.2 & 198.7 & 56.5 & 1269.3 \\
F4 & 278.8 & 219.0 & 59.8 & 1323.1 \\
F5 & 289.9 & 212.9 & 77.0 & 1431.2 \\
F6 & 253.1 & 191.6 & 61.5 & 1416.2 \\
\hline
\end{tabular}

\section{List of Figures}

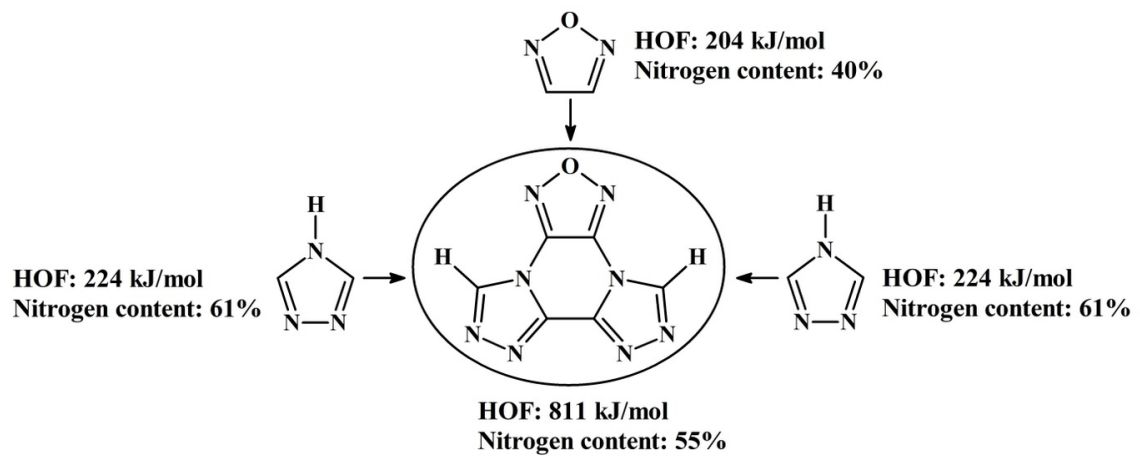

Figure 1. Distinction between fused TTFP and individual rings.<smiles>O=[N+]([O-])c1nnc2c3nnc([N+](=O)[O-])n3c3nonc3n12</smiles>

F6<smiles>O=[N+]([O-])c1nnc2n3c(nnc1-2)-c1nonc1-3</smiles>

F5<smiles></smiles><smiles>[Li]c1nnc2c3nnc(O)n3c3nonc3n12</smiles>

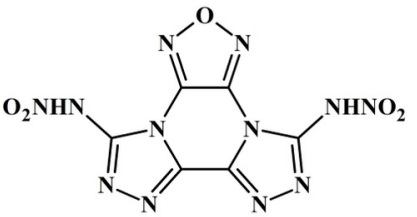

F4<smiles>Nc1nnc2c3nnc(N)n3c3nonc3n12</smiles>

F2<smiles>Nc1nnc2c3nnc(S)n3c3nonc3n12</smiles>

F3

Figure 2 . Designed energetic TTFP derivatives. 


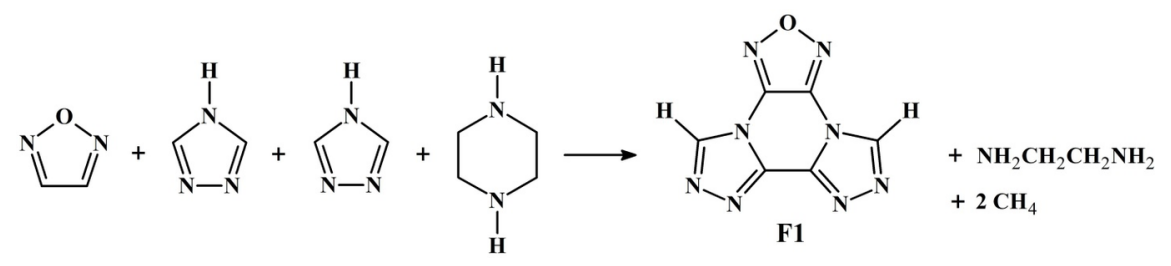

(a)

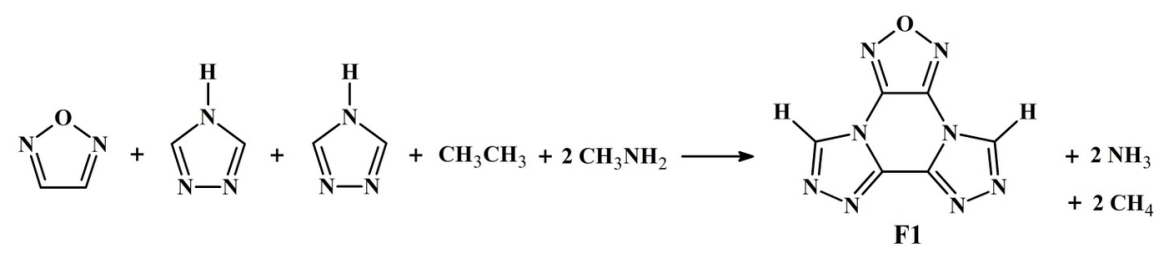

(b)<smiles>[R]C[CH][CH]c1nnc2c3nncn3c3nonc3n12</smiles>

F2: $\mathrm{R}=\mathrm{NH}_{2}$

F3: $\mathrm{R}=\mathrm{N}_{\mathbf{3}}$

F4: $\mathrm{R}=\mathrm{NHNO}_{2}$

F5: $\mathrm{R}=\mathrm{ONO}_{2}$

F6: $\mathrm{R}=\mathrm{NO}_{2}$

(c)

Figure 3. Designed isodesmic reactions ( $\mathrm{a}$ and $\mathrm{b}$ for $\mathrm{F} 1$; c for F2-F6) for the prediction of $\mathrm{HOF}_{\mathrm{Gas}}$. 


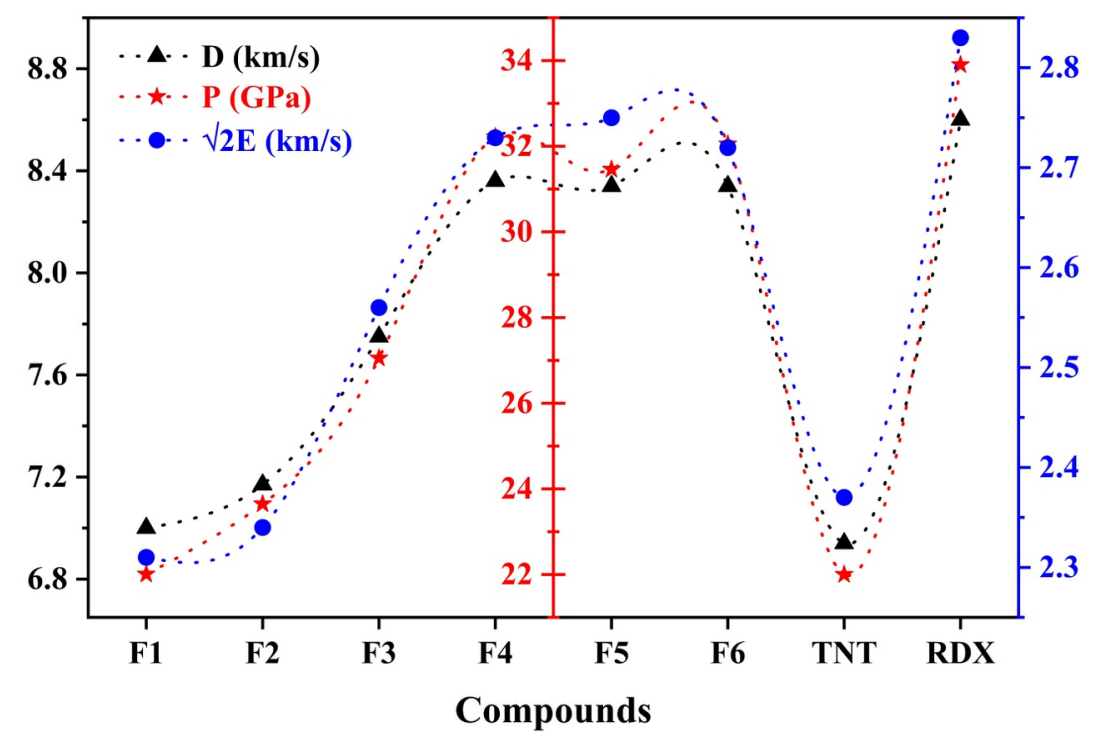

Figure 4 . Comparison of performance properties of the TTFP derivatives with TNT and RDX. 